\title{
Trace metal dynamics in the sediments of a constructed and natural urban tidal marsh: The role of iron, sulfide, and organic complexation
}

\author{
Hagar ElBishlawi ${ }^{\mathrm{a}}$, Jin Young Shin ${ }^{\mathrm{b}}$, Peter R. Jaffe ${ }^{\mathrm{a}, *}$ \\ a Department of Civil and Environmental Engineering, Princeton University, Princeton, NJ 08544, USA \\ ${ }^{\mathrm{b}}$ Meadowlands Environmental Research Institute, 1 DeKorte Park Plaza, Lyndhurst, NJ, USA
}

\section{A R T I C L E I N F O}

\section{Article history:}

Received 17 January 2013

Received in revised form 16 April 2013

Accepted 8 June 2013

\section{Keywords:}

Constructed wetland

Tidal marsh

Sulfide

Trace metals

Organic complexation

Metal immobilization

\begin{abstract}
A B S T R A C T
Two tidal marshes in the New Jersey Meadowlands, one constructed and one natural were characterized to compare their ability to immobilize trace metals $(\mathrm{Cd}, \mathrm{Cr}, \mathrm{Cu}, \mathrm{Mn}, \mathrm{Pb}$, and $\mathrm{Zn})$. Surface and pore waters were sampled four times a year between 2008 and 2010 and sediment cores were collected yearly in the constructed marsh and once in 2010 in the natural marsh. Interactions of trace metals with redox active species such as iron and sulfide as well as with organic matter were investigated. Precipitation with sulfides played a major role in immobilizing certain trace metals, including $\mathrm{Cr}, \mathrm{Mn}$, and $\mathrm{Pb}$. At both sites, the presence of sulfide did not preclude the presence of dissolved trace metals in pore-water at concentrations exceeding their metal sulfide solubility product. Thermodynamic equilibrium modeling indicated these dissolved metals remained in solution due to an association with heterogeneous dissolved organic carbon. No net trace metal accumulation in the surficial sediments of the constructed marsh was noted between 2007 and 2010. This implied that a dynamic equilibrium of trace metal flux into and out of the sediments was established, rather than a long-term net accumulation of trace metals. In the constructed marsh, little difference was found between the immobilization potential in the area of intermittent flooding (high marsh) and the area of sustained flooding (low marsh). The newly constructed wetland immobilized significantly more $\mathrm{Cr}$, $\mathrm{Mn}$, and $\mathrm{Zn}$ than the natural marsh and similar concentrations of $\mathrm{Cd}, \mathrm{Cu}$, and $\mathrm{Pb}$. This may be due to increased redox buffering through a larger FeS buffering pool against tidally induced oxygen delivery.
\end{abstract}

(c) 2013 Elsevier B.V. All rights reserved.

\section{Introduction}

Wetlands are known to interact through biological, geochemical, and hydrological processes with chemical elements in surface waters, resulting in immobilization or release of metals (Du Laing, 2008). The New Jersey Meadowlands contain estuaries located in the New York City/Northern New Jersey metropolitan area, where state and federal agencies have increased interests in restoring wetlands. One concern facing the enhanced wetlands is the possible accumulation of contaminants (including trace metals) transported in during tidal inundation and through atmospheric deposition.

Previous studies have reported: "The accumulation of metals in sediments is substantial in coastal estuaries located within highly urbanized and industrialized areas" (Wenning et al., 1994). Also, in a constructed marsh in this region not affected by tides, Suntornvongsagul et al. report an "accumulation of heavy metals

\footnotetext{
* Corresponding author. Tel.: +1 6092584653; fax: +1 6092582760.

E-mail addresses: helbishl@princeton.edu (H. ElBishlawi), JinYoung.Shin@njmeadowlands.gov (J.Y.Shin), jaffe@princeton.edu (P.R. Jaffe).
}

was observed" (2007). However, precipitated metals are not necessarily fixed permanently in sediments as natural conditions change (s.a. redox changes) (Sundelin and Erikkson, 2001). Whether deposition will result in cumulative, stable, and gradually increasing immobilized loads of trace metals in the sediments, or if tidal dynamics and sediment geochemical processes prevent such a continuous accumulation is currently unclear.

One important pathway to metal immobilization is related to sulfate reduction and the resulting formation of sulfide rich sediment. Metals can form insoluble metal sulfides that result in low bioavailability (Sundelin and Erikkson, 2001). The sequential utilization of electron acceptors during the degradation of organic carbon drives the biogeochemical dynamics in the sediments of a wetland system. Organic carbon is mainly delivered by plant turnover (above- and below-ground biomass) and from root exudates. The biodegradation of this organic matter occurs in order of decreasing energy yield via aerobic oxidation, nitrate reduction, manganese reduction, iron reduction, sulfate reduction, and methanogenesis. Sulfide production is visually observable by a black coloration of sediments and a characteristic sulfide odor released when the marsh surface is disturbed. Other important 
processes governing metal distribution include adsorption and formation of various soluble complexes such as with organic ligands (Vymazal et al., 2010). While the precipitation of trace metals with sulfides (Eq. (1)) result in their immobilization, complexation with dissolved organic ligands, abundant in organic rich marsh sediments, can result in mobilization (Eq. (2)). This system is further complicated by a) adsorption/co-precipitation and b) competition of trace metals with iron (for sulfide and organics).

$\mathrm{Me}^{2+}+\mathrm{S}^{2-} \leftrightarrow \mathrm{MeS}$

$\mathrm{Me}^{2+}+\operatorname{Org} \leftrightarrow$ MeOrg

In tidal wetlands, the complexities of tidal cycles and their effects on the hydrology and biogeochemistry need to be considered in addition to the biogeochemical processes (Catallo, 2003; Du Laing, 2008; Ma et al., 2008; Seybold, 2002; Taillefert, 2002). Depending on hydrologic conditions, marsh soils can be a) flooded with water levels above the surface, b) saturated with no excess flood-waters, or c) with water level below surface to a certain depth (Inglett et al., 2005). Marsh sediment characteristics are affected by tidal influences due to topographical differences. Sediments at regions of higher elevation, hereby denoted as "high marsh", experience intermittent flooding and hence oxic/anoxic periods depending on the stage of the tidal cycle. Sediments at lower elevations, referred to as "low marsh", are usually inundated with water and remain relatively anoxic throughout the tidal cycle.

This study aims at determining the range of trace metal concentrations in pore water and sediments and examine the potential accumulation of metals in sediments of a constructed marsh and compare its progression to that of a natural marsh.

Factors controlling trace metal distribution were investigated to determine if and how they differed between a natural and constructed marsh. Soil pore-water and sediment samples were taken over a between 2008 and 2010) to determine and contrast the influences of biogeochemical mechanisms at the two sites. 1) The effect of seasonality and time 2 ) the effect of the redox gradient (depth profiles up to $60 \mathrm{~cm}$ with $3 \mathrm{~cm}$ resolution), 3) the effect of inundation (low and high topographical elevations), and 4) the effect of mitigation (newly constructed vs. natural marsh sediments) were studied.

\section{Methodology}

\subsection{Site description}

To contrast the factors affecting metal transport in newly constructed and natural urban tidal marshes, pore-water and sediment samples were collected at specified intervals of depth $(0-60 \mathrm{~cm})$ and time (four times a year) between 2008 and 2010. One of the wetlands is a constructed wetland, referred to here as the Secaucus High School constructed marsh, which was completed in 2007. This forty-three acre site is located in the New Jersey Meadowlands (40.804, -74.047) (Fig. 1).

The high marsh areas of the constructed wetland at Secaucus High School were developed by removing approximately $0.5 \mathrm{~m}$ of surface sediment with Phragmites saturated rhizomes. The replacement surface layer was restored with the addition of clean, engineered sediments, consisting of a core of freshwater pond dredge and a $15 \mathrm{~cm}$ cap of sand. The material tapers toward the periphery of the marsh areas. Measurements of source material were not conducted, but analysis was taken shortly after the sediment was applied. Results of report by MERI conducted on April 2007 are presented in Supplementary Table 2 (2011). The sediment of the constructed high marsh had lower metal concentrations
$(0-25 \mathrm{~cm})$ as compared with deeper original sediment $(>25 \mathrm{~cm})$. The low marsh surface and deeper metal concentrations were not very different, implying that the freshly added surface layer is less than $25 \mathrm{~cm}$ in thickness toward the edge. Previously cut off from the tidal influence of the Hackensack River, the marsh was restored to tidal fluctuations in 2008 .

Low and high marsh zones were developed by varying the topography of the fill sediments during construction. The low marsh remains saturated, and usually only exposed during low to mid tides. The high marsh is intermittently flooded with inundation occurring during spring tides. The reference marsh is a natural high marsh located approximately four miles downstream from the constructed marsh $(40.771,-74.086)$ (Fig. 1). The natural marsh experienced higher salinity than the constructed marsh with salinity values of $17.2 \pm 2.3 \mathrm{ppt}$ and $15.0 \pm 1.7 \mathrm{ppt}$, respectively ( $p<0.001$ with 120 samples taken). The pore-waters of the constructed low marsh exhibited slightly more basic conditions than the high marshes with a pH of $6.80 \pm 0.23$ and $6.64 \pm 0.25$, respectively ( $p<0.001$ with 192 samples taken). Dominant plants in the wetlands included Phragmites australis, Spartina patens, and Spartina alterniflora.

\subsection{Pore-water analysis}

Dialysis samplers were deployed to measure chemical profiles of pore-waters without disturbing surrounding sediments. The use of such dialysis samplers has been widely described (Steinmann, 1996; Webster, 1998; Choi et al., 2006). Because seasonal sampling was conducted, modified dialysis samplers were utilized that allowed for collection of pore-water without having to excavate the samplers and disturb sediments. This eliminated the variability on the sampling process due to spatial heterogeneity. MacDonald et al. describe these samplers in detail (2012). Briefly, twenty chambers spaced at $4 \mathrm{~cm}$ intervals up to a depth of $60 \mathrm{~cm}$ were perforated into a plastic block $(8.89 \mathrm{~cm} \times 3.81 \mathrm{~cm} \times 89.41 \mathrm{~cm})$ and were covered by a $0.2 \mu \mathrm{m}$ membrane (GE) and secured with a rubber gasket and a plastic frame. Two capped polypropene tubes connected to each chamber (one at the top and one at the bottom) allowed for the in situ sample withdrawal and input of fill gas (argon) during sampling, and deoxygenated and deionized water (DDIW) after sampling. The volume of each chamber was approximately $60 \mathrm{~mL}$ with a sediment contact area of $0.127 \mathrm{~cm}^{2} \mathrm{~mL}^{-1}$. Prior to placement, plastic parts were washed in $5 \%$ nitric acid and deionized water. Tubes attached to one side of chamber drew in argon gas as syringes withdrew water samples from another tube connecting to the same chamber. Following sampling, the chambers of the dialysis samplers were refilled with DDIW. DDIW-filled chambers were allowed to equilibrate with the sediment pore-waters for at least 4 weeks before sampling. In addition, grab samples of surface water were taken from the channel.

At least four times a year, samples were taken over low and high tide periods and immediately measured for $\mathrm{pH}$, conductivity, and temperature. Samplers were clustered to allow for triplicate measurements at each location in the constructed marsh and duplicate measurements at the natural marsh. To preserve samples for measurement of standard ions and dissolved organic carbon (DOC), $8 \mathrm{~mL}$ of pore-water was acidified with $0.1 \mathrm{~mL}$ of $2 \mathrm{~N} \mathrm{HCl}$ (final concentration $0.025 \mathrm{~N}, \mathrm{pH}<2$ ). Dissolved metals were acidified with concentrated nitric acid to $\mathrm{pH}<2$. To minimize sample loss and oxidation of dissolved sulfide, pore-water was preserved using $15 \mathrm{M}$ sodium hydroxide (final concentration $0.075 \mathrm{M}, \mathrm{pH}>11$ ) and ascorbic acid (final concentration $0.023 \mathrm{M}$ ). These samples were measured upon return to laboratory within hours as described by Liao (2007). All specimens were cooled to $4{ }^{\circ} \mathrm{C}$ until analyzed. 


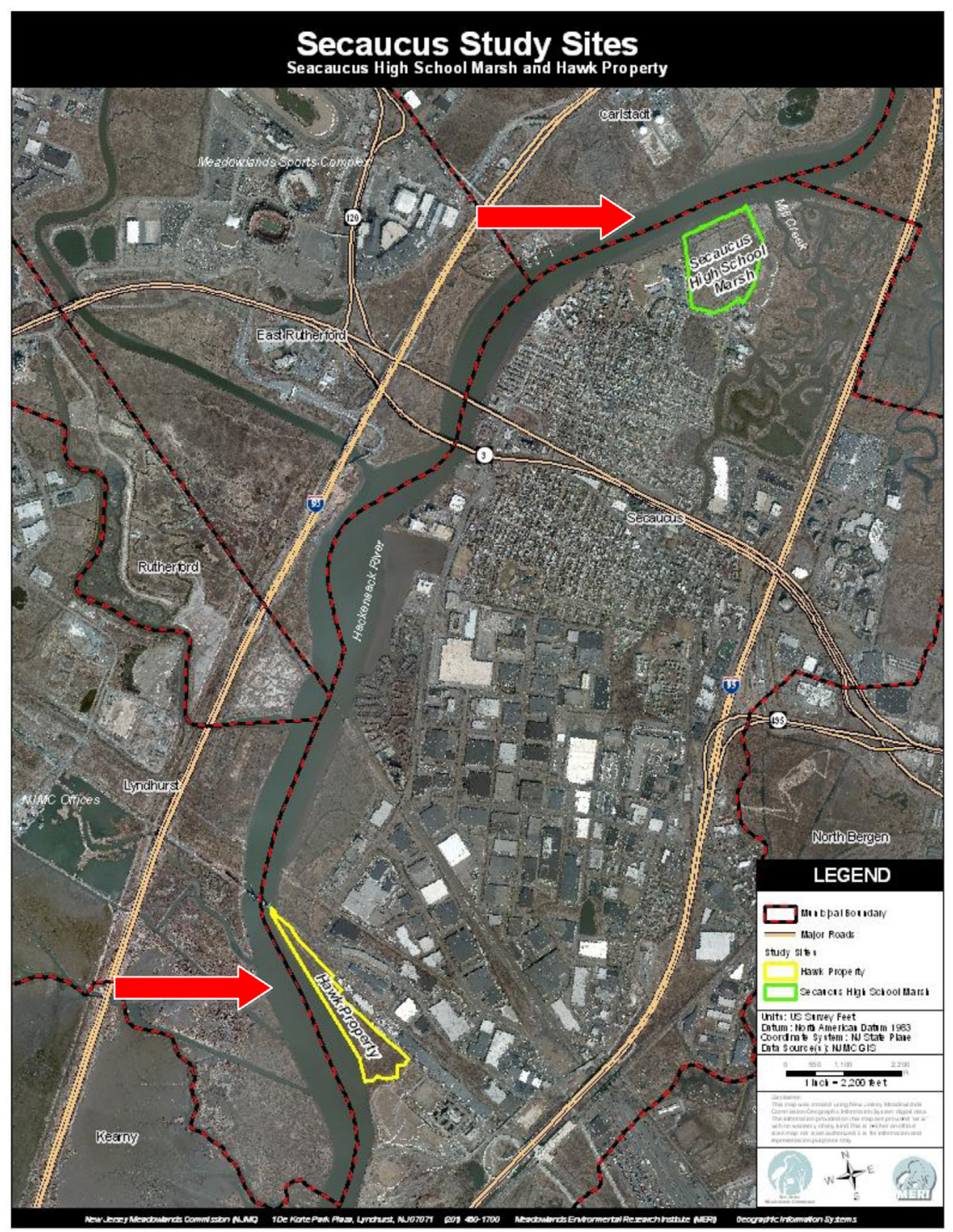

Fig. 1. Location of tidal brackish wetlands along the Hackensack River in Secaucus, NJ, USA. The constructed Secaucus High School Marsh (SHS), completed in 2007, and the reference naturally established marsh (Hawk Property), four miles apart, are indicated by arrows and highlighted in green and yellow respectively. (For interpretation of the references to color in this artwork, the reader is referred to the web version of the article.)

Standard anions (nitrate and sulfate) were measured using ion chromatography (IC). Measurements were taken conducted a Dionex ICS 3000 ion chromatograph equipped with a CD25 conductivity detector and a Dionex IonPac AS22-4mm column. Spectroscopy was as used to measure $\mathrm{Fe}^{2+}$ and total Fe (Thermo Fisher Scientific Spectronic Genesys 2 UV-Vis Spectrophotometer) and $\mathrm{H}_{2} \mathrm{~S}$ (Hach Lachat Quik Chem 8500 Method 10-116-29-3-A). $\mathrm{Fe}(\mathrm{III})$ was calculated as the difference between total iron and $\mathrm{Fe}(\mathrm{II})$ using a ferrozine assay as described by Stookey (1970). Dissolved organic carbon was analyzed with Total Carbon/Total Nitrogen Analyzer (Shimadzu). An Atomic Absorption Spectrophotometer (AAS) (Varian SpectrAA-220) was utilized to measure trace metals and select elements including total dissolved $\mathrm{Cd}, \mathrm{Cr}, \mathrm{Cu}, \mathrm{Fe}, \mathrm{Mn}, \mathrm{Pb}$, and Zn.

\subsection{Sediment analysis}

Sediment samples were collected yearly taken from near the surface $(0-25 \mathrm{~cm})$ and at depth $(>25 \mathrm{~cm})$ in triplicate. In September 2010, a more detailed sediment profile was determined using a
Russian peat corer taken in $50 \mathrm{~cm}$ sections with each grab. In the natural marsh, due to the thick root mat, sediment cores could only be withdrawn beginning at a depth of $50 \mathrm{~cm}$. This was supplemented with grab samples from the top $25 \mathrm{~cm}$ of the organic rich marsh sediments. Samples were immediately wrapped with plastic and stored under $\mathrm{N}_{2}$ gas at $4{ }^{\circ} \mathrm{C}$. Percent moisture and solid organic matter were determined for each sample. The vertical distribution of sediment properties was examined following sectioning into $4 \mathrm{~cm}$ depth segments in an anaerobic glove box $\left(3 \%: 97 \% \mathrm{H}_{2}: \mathrm{N}_{2}\right)$ in the laboratory. The $4 \mathrm{~cm}$ segments were placed in plastic bags filled with nitrogen gas and refrigerated until analyzed.

Soil Organic Matter (SOM) in the sediment samples was determined by loss on ignition (Blume et al., 1990; Nelson and Sommers, 1996; ASTM, 2000). Solid-phase metals were extracted using $2 \mathrm{~N}$ $\mathrm{HCl}$ and full strength $\mathrm{HNO}_{3}$ for twenty-four hours with concentration determined via AAS (Rao et al., 2008).

Acid Volatile Sulfide (AVS) represents the operational pool of sedimentary substances generating hydrogen sulfide gas upon addition of hydrochloric acid (Meysman, 2005). AVS measurements were performed on sediment cores retrieved from the two marshes. 
Oxidation of reduced species was minimized by avoiding unnecessary sediment disturbance and by transporting and manipulating the sediments under nitrogen. The AVS method is described in detail in a study by Lasorsa and Casas (1996). Selected samples were sent to Huffman Laboratories, Golden, CO, for independent verification. Briefly, nitrogen gas was bubbled through a vessel containing a sediment sample in $1 \mathrm{~N} \mathrm{HCl}$ for forty-five minutes and the off gases were captured in two traps containing $\mathrm{NaOH}$. Sulfide was measured voltammetrically (AIS DLK 100A) using a thin film mercury electrode in conjunction with a silver/silver chloride reference electrode, and platinum counter electrode (Kovaleva, 2004). AVS Simultaneously Extractable Metals (AVS/SEM) were measured after filtering the acidified sample with a $0.45 \mathrm{um}$ filter and measuring metals using AAS. This measurement of $1 \mathrm{~N} \mathrm{HCl}$ soluble metals represents the fraction of metal species that have been immobilized in sediment.

\subsection{Chemical modeling}

Visual Minteq was utilized to model the speciation of metals in pore-waters. System components included dissolved metals $(\mathrm{Cu}, \mathrm{Cr}, \mathrm{Fe}, \mathrm{Mn}, \mathrm{Pb}, \mathrm{Zn})$, organic carbon, sulfate and sulfide. Initial concentrations were representative of field measurements. Possible solid species present in the basis were FeS; Galena (PbS); Pyrite (FeS); Spharelite ( $\mathrm{ZnS})$. Possible redox couples included: $\mathrm{HS}^{-} / \mathrm{SO}_{4}{ }^{2-} ; \mathrm{Fe}^{2+} / \mathrm{Fe}^{3+}$. Complexation constants for trace metals with dissolved organic matter were obtained from the genericFA database associated with VMinteq v2.61 and values reported in the literature (Van den Berg et al., 1987; Saar and Weber, 1980) (See Supplementary Table 4).

\subsection{Statistical analysis}

Natural and constructed marsh soil and pore-water data were analyzed using ANOVA with factors for the marsh location, depth, and season. Additionally, sediment depth profiles were compared using paired Student's t-test (natural high marsh vs. constructed high marsh, constructed high marsh vs. constructed low marsh, and summer pore-water concentrations vs. other seasons). Trends over time were also tested for significance using linear regression analysis as well as non-parametric Sen's slope estimator.

\section{Results and discussion}

\subsection{Seasonal variations in dissolved constituents}

The natural high marsh exhibited the least inter-seasonal variation in dissolved trace metals compared to the constructed marsh with the exception of iron (Table 1a). Seasonal dissolved concentrations averaged over a depth of $60 \mathrm{~cm}$ between the years 2008 and 2010 are reported in Supplementary Table 1. While the specific period in which the highest concentrations of iron were measured varied between sites (natural and constructed high marshes: spring and constructed low marsh: summer), these seasons coincided with the lowest concentrations of dissolved sulfide in their respective locations. At all sites, DOC was lowest in the spring. The ranges between seasonal DOC values were within an order of magnitude.

\section{2. “Long-term" trends}

Average dissolved metal, sulfate, and carbon values were stable (no significant trends, $p<0.1$ ) over the study period (data not presented). Measurements for solid phase trace metals in the sediments from our study were supplemented with values from the MERI, 2011 report, which had a longer time set between April 2007 and April 2010. Analysis of solid phase temporal trends was performed. Similar to the dissolved phase, all solid phase metals (except $\mathrm{Pb}$ ) measured in the constructed high marsh did not exhibit a significant trend with time using a $95 \%$ confidence interval. Interpreting Sen's slope estimator, surface $\mathrm{Pb}(<25 \mathrm{~cm})$ has no significant trend. A slightly increasing rate of $0.036 \mathrm{mmol} \mathrm{Pb} / \mathrm{kg}$ y was detected in the deeper sediments $(>25 \mathrm{~cm})$. Sen's test implies that in the

Table 1

Geometric mean of (a) dissolved pore-water sampled between 2008 and 2010 and (b) solid sediment collected July 2009 and September 2010 averaged over a depth of $60 \mathrm{~cm}$ in the natural high marsh, constructed high marsh, and constructed low marsh accompanied by geometric standard deviation and sample number.

\begin{tabular}{|c|c|c|c|c|}
\hline a) Dissolved & Nat high mar & Con high mar & Con low mar & Lev sig \\
\hline Cd [uM] & $0.003 \pm 1.745(141)$ & $0.003 \pm 2.384(136)$ & $0.004 \pm 1.879(132)$ & ${ }^{* * *}$ \\
\hline $\mathrm{Cr}[\mathrm{uM}]$ & $0.32 \pm 1.94(313)$ & $0.37 \pm 1.86(493)$ & $0.33 \pm 2.04(350)$ & ${ }^{*}$ \\
\hline $\mathbf{C u}[\mathbf{u M}]$ & $0.13 \pm 2.81(313)$ & $0.06 \pm 3.88(493)$ & $0.13 \pm 3.40(350)$ & $* * *$ \\
\hline $\operatorname{Mn}[\mathbf{u M}]$ & $10.58 \pm 1.69(245)$ & $58.42 \pm 1.92(209)$ & $14.04 \pm 2.77(202)$ & $* * *$ \\
\hline $\mathbf{P b}[\mathbf{u M}]$ & $0.02 \pm 3.33(313)$ & $0.63 \pm 37.78(1045)$ & $0.44 \pm 41.22(625)$ & $* * *$ \\
\hline $\mathrm{Zn}[\mathrm{uM}]$ & $0.88 \pm 1.76(330)$ & $0.71 \pm 2.44(601)$ & $0.72 \pm 3.00(386)$ & ${ }^{* *}$ \\
\hline Fe $[\mathbf{u M}]$ & $2.85 \pm 14.87(419)$ & $151.25 \pm 6.9(902)$ & $46.93 \pm 5.54(438)$ & $* * *$ \\
\hline $\mathrm{NO}_{3}-[\mathrm{mM}]$ & $0.01 \pm 5.34(154)$ & $0.01 \pm 5.93(137)$ & $0.01 \pm 7.67(133)$ & \\
\hline $\mathrm{SO}_{4}^{2}-[\mathrm{mM}]$ & $2.29 \pm 3.02(407)$ & $0.19 \pm 8.00(1004)$ & $0.39 \pm 6.15(741)$ & $* * *$ \\
\hline $\mathrm{H}_{2} \mathrm{~S}[\mathrm{mM}]$ & $1.96 \pm 6.18(181)$ & $0.15 \pm 19.91(216)$ & $0.22 \pm 12.08(225)$ & $* * *$ \\
\hline $\mathrm{DOC}[\mathrm{mg} / \mathrm{L}]$ & $92.26 \pm 2.80(594)$ & $109.12 \pm 2.76(850)$ & $44.74 \pm 2.98(593)$ & $* * *$ \\
\hline b) Solid & Nat high mar & Con high mar & Con low mar & Lev sig \\
\hline $\mathrm{Cd}[\mathrm{mmol} / \mathrm{kg}]$ & $0.003 \pm 29.724(4)$ & $0.004 \pm 1.913(14)$ & $0.003 \pm 3.340(16)$ & \\
\hline $\mathrm{Cr}[\mathrm{mmol} / \mathrm{kg}]$ & $0.06 \pm 3.07(10)$ & $0.17 \pm 3.57(14)$ & $0.2 \pm 5.96(16)$ & \\
\hline $\mathrm{Cu}[\mathrm{mmol} / \mathrm{kg}]$ & $0.09 \pm 7.66(10)$ & $0.11 \pm 5.32(14)$ & $0.07 \pm 12.65(16)$ & \\
\hline $\mathrm{Mn}[\mathrm{mmol} / \mathrm{kg}]$ & $0.26 \pm 1.63(10)$ & $1.37 \pm 2.65(13)$ & $1.50 \pm 2.34(14)$ & $* * *$ \\
\hline $\mathrm{Pb}[\mathrm{mmol} / \mathrm{kg}]$ & $0.10 \pm 7.03(10)$ & $0.21 \pm 3.02(13)$ & $0.16 \pm 5.21(14)$ & \\
\hline $\mathrm{Zn}[\mathrm{mmol} / \mathrm{kg}]$ & $0.27 \pm 2.05(10)$ & $0.73 \pm 2.57(13)$ & $0.75 \pm 2.75(14)$ & ${ }^{*}$ \\
\hline $\mathrm{Fe}($ II) $[\mathrm{mmol} / \mathrm{kg}]$ & $4.36 \pm 2.78(8)$ & $17.76 \pm 2.41(16)$ & $25.15 \pm 2.65(17)$ & $* * *$ \\
\hline TotFe $[\mathrm{mmol} / \mathrm{kg}]$ & $3.38 \pm 2.33(10)$ & $113.15 \pm 2.41(13)$ & $59.05 \pm 4.95(16)$ & $* * *$ \\
\hline AVS [mmol/kg] & $21.12 \pm 1.46(14)$ & $8.47 \pm 1.2(14)$ & $10.76 \pm 1.37(16)$ & $* * *$ \\
\hline SOM [\%] & $36.68 \pm 1.28(10)$ & $5.12 \pm 2.87(14)$ & $17.3 \pm 3.35(16)$ & $* * *$ \\
\hline
\end{tabular}

Levels of significance $p<0.001$ indicated in bold.

${ }^{*} p<0.05$.

** $p<0.01$.

*** $p<0.001$. 
constructed low marsh, $\mathrm{Cr}$ is decreasing in the deeper sediments $(-3.12 \mathrm{mmol} \mathrm{Cr} / \mathrm{kgy})$ and copper is slightly decreasing $(-0.36$ to $-0.48 \mathrm{mmol} \mathrm{Cu} / \mathrm{kg} \mathrm{y})$.

\subsection{Comparing the natural and constructed marshes: dissolved metals and other constituents}

Pore water samples collected up to depth of $60 \mathrm{~cm}$ between 2008 and 2010 and were analyzed for their dissolved phase constituents in the natural high, constructed high, and constructed low marshes. The geometric mean, standard deviation, sample number, and level of significance are presented in Table 1a. There were significant differences between sites with high $p$-levels $(<0.001)$ in concentrations of $\mathrm{Cd}, \mathrm{Cu}, \mathrm{Mn}, \mathrm{Pb}, \mathrm{Fe}, \mathrm{SO}_{4}{ }^{2-}, \mathrm{H}_{2} \mathrm{~S}$, and DOC. The natural high marsh exhibited the lowest concentrations of these dissolved metals and highest concentrations of $\mathrm{SO}_{4}{ }^{2-}$ and $\mathrm{H}_{2} \mathrm{~S}$. Conversely, the constructed high marsh displayed the highest values of most of these mobilized dissolved metals and the lowest values of $\mathrm{SO}_{4}{ }^{2-}$ and dissolved $\mathrm{H}_{2} \mathrm{~S}$. The constructed low marsh displayed mostly intermediate or similar concentrations to the natural and constructed high marshes. DOC was abundant at all sites, but with highest values measured in the constructed high marsh, natural high marsh, and constructed low marsh, respectively. Between the sites, dissolved $\mathrm{Cd}, \mathrm{Cr}, \mathrm{Cu}, \mathrm{Zn}$, and $\mathrm{NO}_{3}{ }^{-}$concentrations did not vary greatly.

\subsection{Comparing the natural and constructed marshes: solid-phase metals and other constituents}

Sediment cores collected over a depth of $60 \mathrm{~cm}$ in July 2009 and September 2010 were used to determine the distribution of metals and other analytes in the solid phase. The geometric mean, standard deviation, sample number, and level of significance are presented in Table 1b. Higher concentrations of all trace metals were measured in the constructed marsh, as compared to the natural marsh. Within the constructed marsh, greater concentrations of $\mathrm{Pb}$ and $\mathrm{Cu}$ were measured in the high marsh, while all other trace metal values were not significantly different from the low marsh $(p<0.01)$. Solid phase associated $\mathrm{Fe}^{2+}$ concentrations did vary significantly between sites with lowest iron concentration found in the natural high marsh. Comparing $\mathrm{Fe}^{2+}$ and total iron, we observe that in the constructed marsh, $\mathrm{Fe}^{3+}$ is still readily available while in the natural marsh, most of the iron exists as $\mathrm{Fe}^{2+}$. Acid volatile sulfide (AVS) was significantly higher in the natural marsh followed by the constructed low marsh, and the constructed high marsh, replicating trends of the dissolved phase sulfide.

\subsection{Electron donor and TEA/reduced species depth profiles}

Depth profiles of the major electron donor: DOC, and terminal electron acceptors or their reduced species: dissolved $\mathrm{Fe}^{2+}$, $\mathrm{SO}_{4}{ }^{2-}$, and $\mathrm{H}_{2} \mathrm{~S}$ are reported in Fig. 2 with average values listed in Table 1a. Highest values of DOC were measured in the high marshes of the constructed and natural sites. The low marsh exhibited the lowest concentrations of DOC. All sites displayed higher DOC concentrations below $50 \mathrm{~cm}$ as compared to surface values. Because the redox gradient is superimposed on the depth profile (i.e. more reducing condition with depth) more energetically favorable reactions should occur closer to the surface. This would result in greater DOC degradation at shallower depths and ultimately less storage. Little dissolved nitrate was found in any of the pore-water samples (see Table 1 ) and values were uniform with depth (not shown). Dissolved iron increased with depth in the natural high marsh, but with concentrations significantly lower than in the constructed marsh. In the constructed high marsh, iron concentrations decreased toward a concentration similar to those in the natural high marsh below $50 \mathrm{~cm}$. The constructed low marsh was intermediate in its iron concentrations, which decreased below $30 \mathrm{~cm}$. Sulfate concentration decreased below $10 \mathrm{~cm}$ in the constructed marsh and sulfide concentrations increased with depth reaching concentrations similar to the natural marsh below $30 \mathrm{~cm}$ indicating sulfate reduction. The sulfate concentrations did not decrease with depth and sulfide remained relatively stable in concentration with depth in the natural high marsh.

\subsection{Trace metal depth profiles}

Dissolved trace metal profiles are reported in Supplementary Fig. 1 with averages listed in Table 1a. Of the dissolved trace metals measured, all showed uniform concentration profiles with depth except for $\mathrm{Cu}, \mathrm{Mn}$, and $\mathrm{Pb}$. Dissolved $\mathrm{Cu}$ concentrations were highest near the surface and decrease with depth up to about $5 \mathrm{~cm}$ (natural high marsh), $20 \mathrm{~cm}$ (constructed high marsh), and $40 \mathrm{~cm}$ (constructed low marsh). The concentrations then converge to a steady concentration profile. The $\mathrm{Pb}$ profile in the natural marsh is smaller in concentration and uniform as compared to the constructed marsh. $\mathrm{Pb}$ increased to a maximum at about $10 \mathrm{~cm}$ and then stabilized in concentration. The Mn profile was uniform in the natural high and constructed low marshes, but increased to a maximum at $15 \mathrm{~cm}$ and remained constant in the constructed high marsh. While the dissolved metal pool did not vary greatly with depth, concentrations remained measurable in solution despite the availability of dissolved sulfide and those metals affinity to form precipitates with $\mathrm{H}_{2} \mathrm{~S}$.

Sediment depth profiles of solid-phase metals are shown in Fig. 3 with average values reported in Table 1b. The solid trace metals generally displayed maximum concentrations at approximately $15 \mathrm{~cm}$ where the values then decreased or remained constant converging to similar concentrations across sites below $60 \mathrm{~cm}(\mathrm{Cd}, \mathrm{Cr}, \mathrm{Mn}, \mathrm{Zn})$. This depth coincides with the region where dissolved iron stops increasing and sulfate begins to decrease. Most likely, the formation of insoluble iron sulfide promotes the co-precipitation of these trace metals. The solid $\mathrm{Cu}$ concentration profile, exhibited maximum values near the surface in the natural high marsh and constructed low marsh (values decreased with depth). Also, maximum solid $\mathrm{Pb}$ concentrations did not converge between the 3 locations, unlike other metals measured.

\subsection{Vertical stratification in sediment of constructed marsh: solid carbon depth profiles}

When factoring depth into the analysis of variance, significant differences between the three sites $(p<0.05)$ were observed (Fig. 4 ). The SOM sediment profile in the natural high marsh varied little with depth. A SOM mean of $37 \%$ was measured which corresponded to a visually observable thick root mat in surface sediments. In the constructed marsh, the surface sediments contained less SOM and then increased with depth rapidly to values similar to the natural marsh deeper in the sediment. The sediment of the constructed marsh was visibly sandier near the surface and became darker in color and richer in organic material with depth. In the constructed high marsh the SOM increased rapidly from 5\% to $38 \%$ at depths below $54 \mathrm{~cm}$. Similarly, the constructed low marsh showed stratification in the SOM profile with an increase from $4 \%$ to $31 \%$ at a depth of $20 \mathrm{~cm}$. Four years after the completion of the constructed marsh, stratification of new and old sediment was still measurable in terms of SOM values. The shallower sediments with lower organic content in the constructed marsh represent the new 
(a)

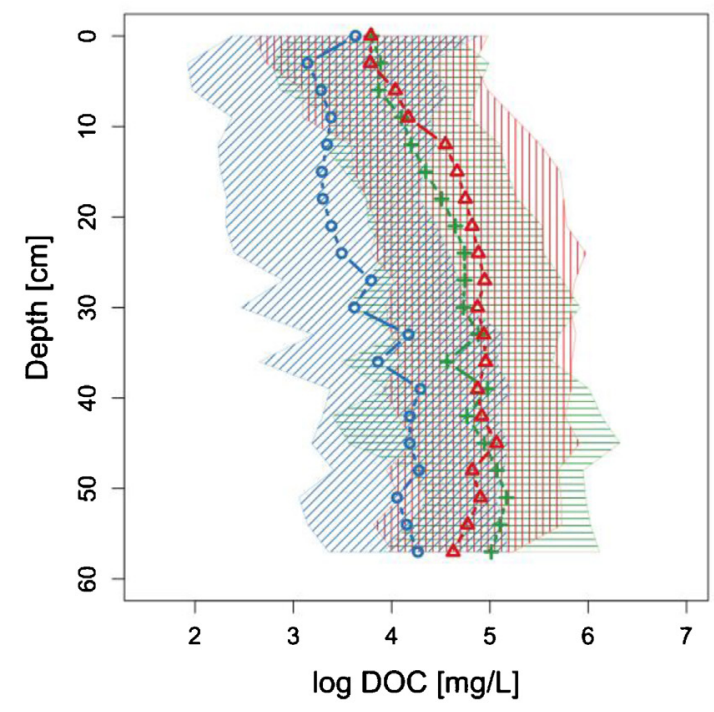

(c)

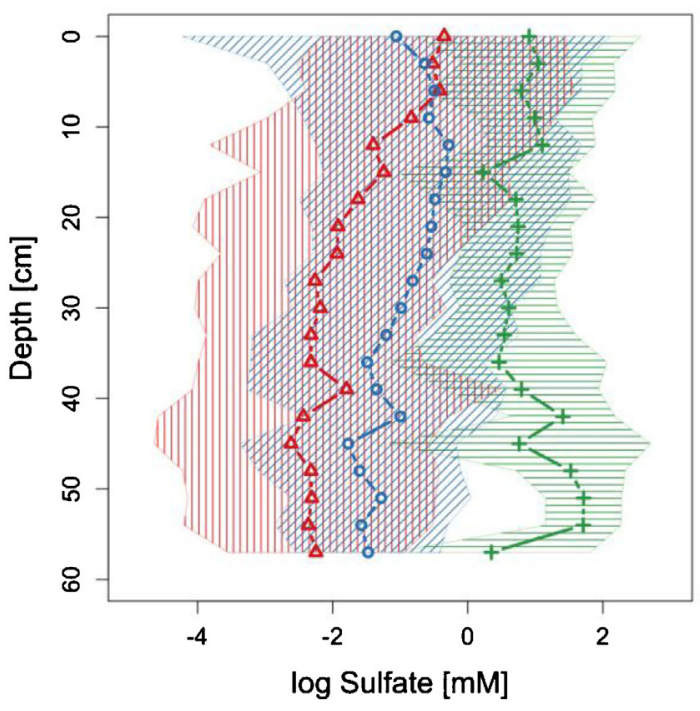

(b)

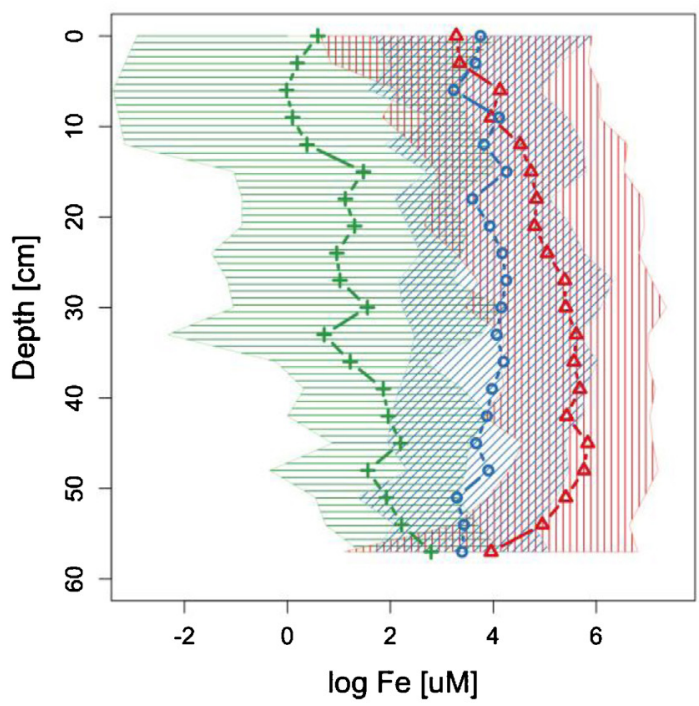

(d)

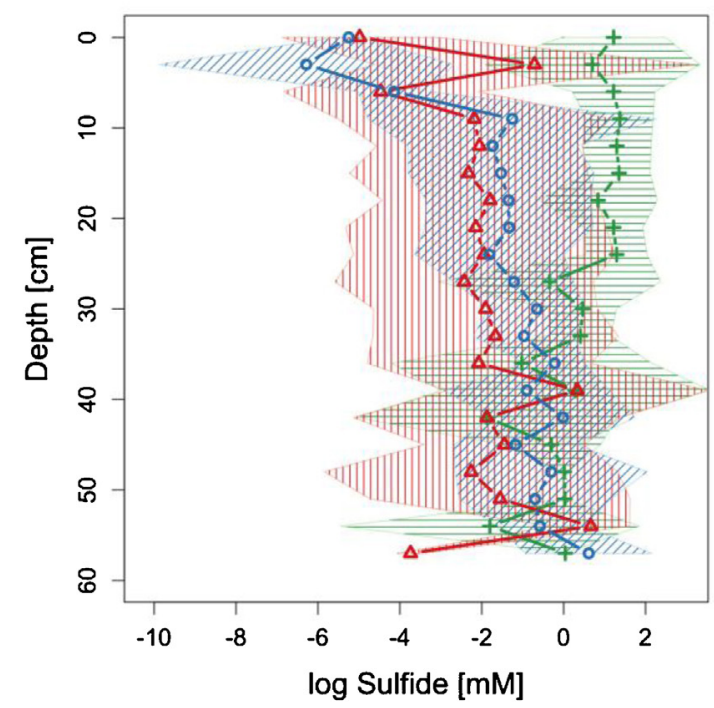

Fig. 2. Depth profiles of average dissolved (a) organic carbon,(b) iron, (c) sulfate, and (d) sulfide in the natural high marsh (+ [horizontal]), constructed high marsh ( $\Delta$ [vertical]), and constructed low marsh (O [angled]) between 2008 and 2010 with hatching indicating 1 standard deviation. The high marshes exhibit higher DOC concentrations. The constructed high and low marshes have an abundance of $\mathrm{Fe}^{2+}$. Sulfate reduction is observed below $10 \mathrm{~cm}$ in the constructed marsh (characteristic decrease in sulfate accompanied by increase in sulfide concentrations). Sulfide/sulfate appear to be in equilibrium in the natural high marsh pore waters.

sediments, added while constructing the marsh, while the more organic rich sediments represent the original sediments.

\subsection{Vertical stratification in sediment of constructed marsh: solid iron and sulfide depth profiles}

The vertical depth profiles of solid iron and sulfide in the constructed marsh are reported in Fig. 5 with average values listed in Table 1b. The stratification patterns observed in the SOM values are mirrored in the solid iron concentrations. While the SOM exhibited discrete discontinuities from lower to high concentration at the intersection of new and old sediments, decreases in the iron concentrations are observed in the constructed high marsh. The concentrations of iron and sulfide converged below 54 and $20 \mathrm{~cm}$ in the constructed high and low marshes respectively. This indicates a change in solid-phase iron concentration, which had decreased to values equal to solid-phase sulfide, highlighting the interface between the new and old sediments. Additionally, in the constructed marsh above the interface, Fe is greater than AVS and below Fe equals AVS. The solid iron concentrations are less than or equal to AVS throughout the depth profile. In the constructed marsh, Fe is greater than AVS at depths of less than $40 \mathrm{~cm}$ (high marsh) and $30 \mathrm{~cm}$ (low marsh). Higher levels of extractable Fe(II) are most likely the result of the reduction of $\mathrm{Fe}(\mathrm{III})$ and incorporation of $\mathrm{Fe}(\mathrm{II})$ phases into the Fe minerals still present in the newly applied soil. This was qualitatively determined by observation of ferromagnetic properties of the sediment. This difference in concentration between Fe and AVS in the newer surface sediments may be explained by the presence of magnetite in the amended surface sediments of the constructed marsh. 
a) Cadmium

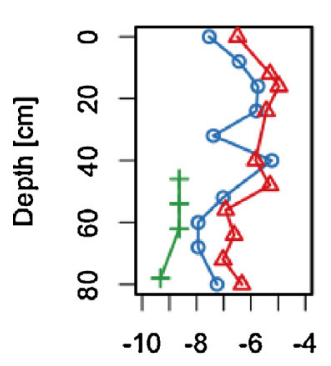

[log $\mathrm{mmol} \mathrm{Cd} / \mathrm{kg} \mathrm{sed}]$ b) Chromium

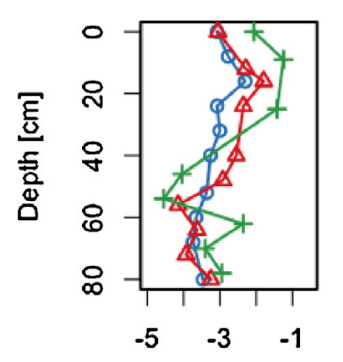

$[\log \mathrm{mmol} \mathrm{Cr} / \mathrm{kg} \mathrm{sed}]$ c) Copper

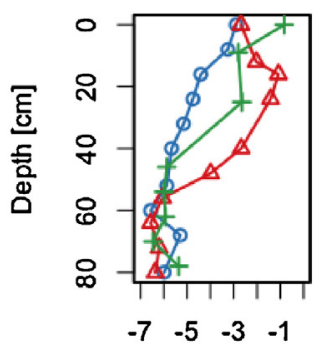

[log mmol Cu/kg sed] d) Manganese

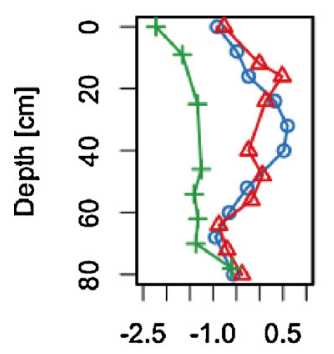

$[\log \mathrm{mmol} \mathrm{Mn} / \mathrm{kg}$ sed] e) Lead

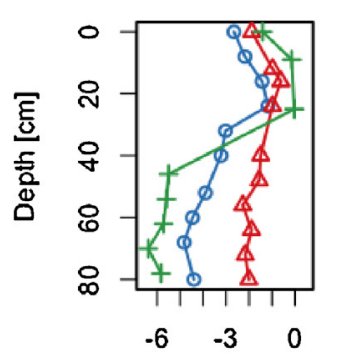

[log mmol Pb/kg sed] f) Zinc

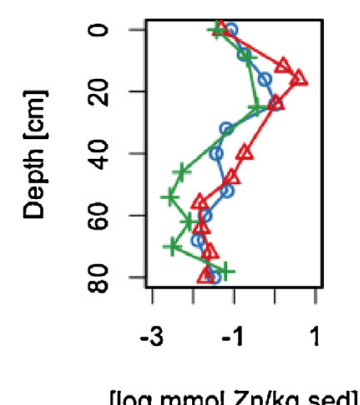

Fig. 3. Vertical distribution of solid phase trace metals in (+) natural high marsh, $(\Delta)$ constructed high marsh, and $(0)$ constructed low marsh collected in September 2010 with significant differences found only for $\mathrm{Mn}$ and $\mathrm{Pb}$.

\subsection{Correlations, chemical modeling, and DOC complexing capacity}

The natural high marsh had the highest concentrations of dissolved sulfide, while the constructed high marsh exhibited the

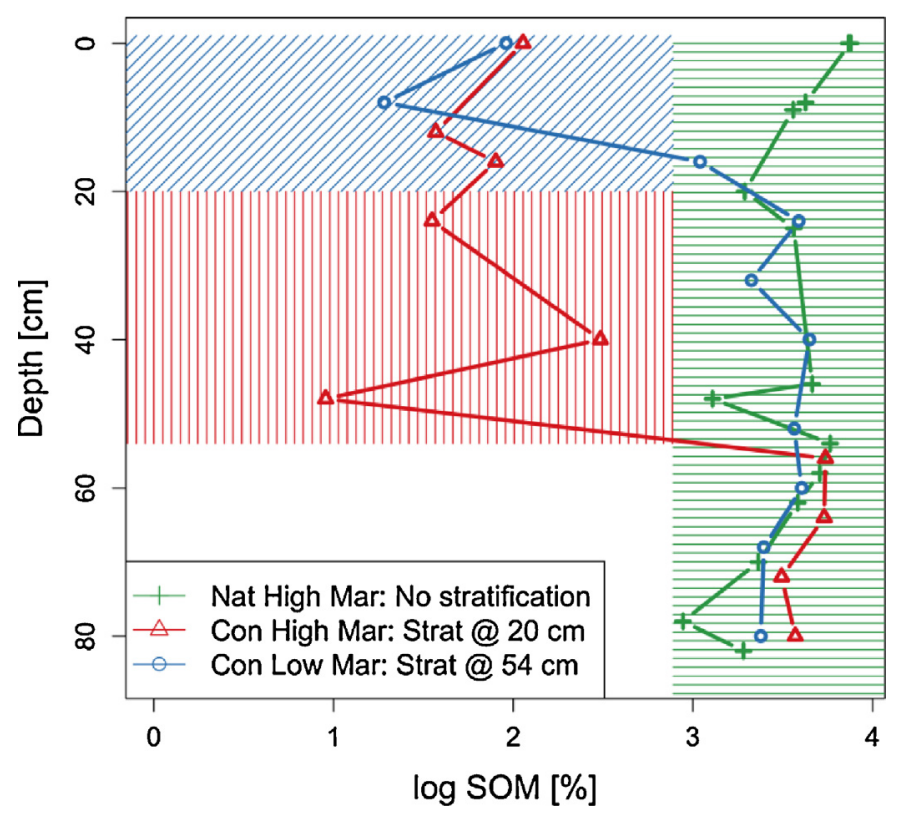

Fig. 4. The Soil Organic Matter (SOM) profile at the $(+)$ natural high marsh, $(\Delta)$ constructed high marsh, and $(\mathrm{O})$ constructed low marsh sampled September 2010. No stratification was observed for natural high marsh. SOM values at constructed site increase to "natural" values at depth of $54 \mathrm{~cm}$ (high marsh) and $20 \mathrm{~cm}$ (low marsh), indicating the zonation of the newly applied and original sediments. highest concentrations of both $\mathrm{DOC}$ and $\mathrm{Fe}^{2+}(\mathrm{aq})$. Intermediate values of $\mathrm{Fe}^{2+}(\mathrm{aq})$ and $\mathrm{H}_{2} \mathrm{~S}(\mathrm{aq})$ were observed in the constructed low marsh. With a larger pool of sulfides available, greater metal immobilization in sediments was expected in the natural high marsh. Yet, for all trace metals ( $\mathrm{Cd}, \mathrm{Cr}, \mathrm{Cu}, \mathrm{Mn}, \mathrm{Pb}$, and $\mathrm{Zn}$ ) higher concentrations were measured in the constructed marsh. To discern the relative effect of $\mathrm{DOC}, \mathrm{Fe}^{2+}(\mathrm{aq}), \mathrm{H}_{2} \mathrm{~S}(\mathrm{aq})$, and other parameters on dissolved metal variation, correlations between these species were determined (Table 2 ). Trace metals that appeared significantly
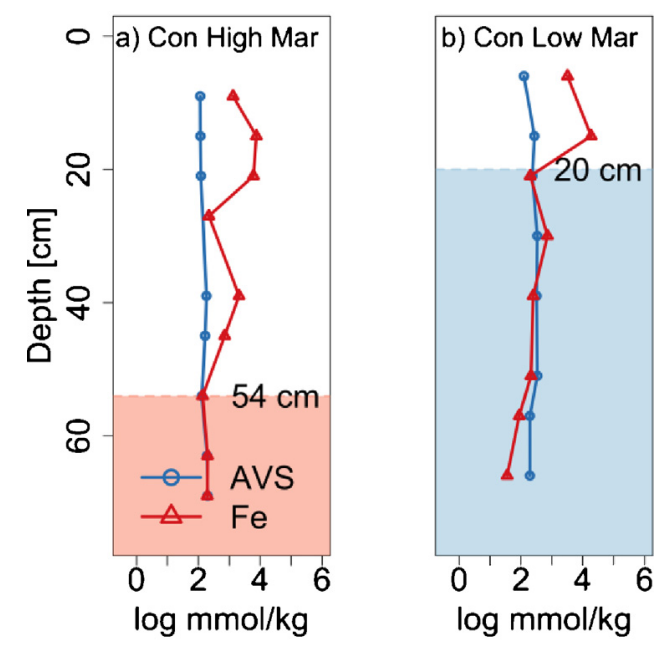

Fig. 5. Acid Volatile Sulfide (AVS) concentrations and accompanying iron concentrations for the constructed high and low marsh sediments collected September 2010. Concentrations of Fe(II) are greater than AVS in the amended sediments, but become equal below $54 \mathrm{~cm}$ (constructed high marsh) and below $20 \mathrm{~cm}$ (constructed low marsh). 
Table 2

Pearson correlation coefficients with $R^{2} \geq|0.2|$ indicated in bold and $R^{2} \geq|0.5|$ starred for specified dissolved components.

\begin{tabular}{lllllll}
\hline Analyte & $\mathrm{H}_{2} \mathrm{~S}$ & $\mathrm{Fe}^{2+}$ & $\mathrm{DOC}$ & Salinity & $\mathrm{pH}$ & Depth \\
\hline $\mathrm{Cd}$ & 0.1 & -0.1 & $-0.5^{*}$ & -0.2 & -0.1 & -0.1 \\
$\mathrm{Cr}$ & $-\mathbf{0 . 5}$ & $\mathbf{0 . 4}$ & 0.0 & $-\mathbf{0 . 3}$ & 0.1 & -0.1 \\
$\mathrm{Cu}$ & -0.1 & $-\mathbf{0 . 4}$ & $-\mathbf{0 . 4}$ & $-\mathbf{0 . 2}$ & $-\mathbf{0 . 2}$ & $-\mathbf{0 . 2}$ \\
$\mathrm{Mn}$ & $-\mathbf{0 . 4}$ & $\mathbf{0 . 7 ^ { * }}$ & $\mathbf{0 . 5}$ & $-\mathbf{0 . 2}$ & $\mathbf{0 . 3}$ & $\mathbf{0 . 2}$ \\
$\mathrm{Pb}$ & $-\mathbf{0 . 5}$ & $\mathbf{0 . 9}^{*}$ & $-\mathbf{0 . 2}$ & $-\mathbf{0 . 5}^{*}$ & $\mathbf{0 . 6}^{*}$ & 0.1 \\
$\mathrm{Zn}$ & 0.0 & $-\mathbf{0 . 3}$ & $\mathbf{0 . 2}$ & 0.1 & $-\mathbf{0 . 3}^{*}$ & $-\mathbf{0 . 3}$ \\
$\mathrm{Fe}$ & $-\mathbf{0 . 5}$ & - & 0.1 & $-\mathbf{0 . 5}$ & $-\mathbf{0 . 6}^{*}$ & $\mathbf{0 . 2}$ \\
$\mathrm{SO}_{4}{ }^{2-}$ & $\mathbf{0 . 4}$ & $-\mathbf{0 . 9}^{*}$ & -0.1 & $-\mathbf{0 . 4}$ & $-\mathbf{0 . 5}^{*}$ & $-\mathbf{0 . 2}$ \\
$\mathrm{H}_{2} \mathrm{~S}$ & - & $-\mathbf{0 . 5}$ & $\mathbf{0 . 3}$ & $\mathbf{0 . 3}$ & $-\mathbf{0 . 5}$ & $\mathbf{0 . 2}$ \\
$\mathrm{DOC}$ & $\mathbf{0 . 3}$ & 0.1 & - & $\mathbf{0 . 2}$ & $-\mathbf{0 . 2}$ & $\mathbf{0 . 6}$ \\
\hline
\end{tabular}

different $(p<0.001)$ between the natural and constructed marshes: $\mathrm{Mn}$ and $\mathrm{Pb}$ showed that $\mathrm{H}_{2} \mathrm{~S}(\mathrm{aq}), \mathrm{Fe}^{2+}$, and $\mathrm{DOC}$ all have an effect on their variance. Dissolved $\mathrm{Cd}, \mathrm{Cr}, \mathrm{Cu}$, and $\mathrm{Zn}$, did not vary greatly by location and had a strong correlation with either $\mathrm{H}_{2} \mathrm{~S}$ $(\mathrm{Cr})$ or DOC ( $\mathrm{Cd}, \mathrm{Cu}$, and $\mathrm{Zn})$ but not both. Iron correlated with all metals sampled except $\mathrm{Cd}$, but the direction of the trend varied. All trace metals measured except $\mathrm{Cr}$ exhibited a correlation with DOC.

$\mathrm{Cd}, \mathrm{Cr}, \mathrm{Cu}, \mathrm{Mn}, \mathrm{Pb}$, and $\mathrm{Zn}$ form highly insoluble precipitates with sulfide. Yet, the data revealed that measurable concentrations of dissolved metals were present with dissolved sulfide above predicted their solubility for all trace metals in the natural high marsh and for $\mathrm{Cu}$ and $\mathrm{Pb}$ in the constructed marsh (Supplementary Table 3). Organic ligands are known to be able to bind with metals to form soluble complexes (Guy and Chakrabarti, 1976). If metal complexation with ligands precludes association with sulfides as a precipitate, dissolved metals would be found in the marsh porewaters even in the presence of sulfide. To determine the relative importance of organic ligands and sulfide associations with trace metals, a thermodynamic equilibrium model of the system was implemented utilizing the Visual Minteq program. Supplementary Table 4 lists model parameters utilized for the simulations. Average values for $\mathrm{DOC}, \mathrm{Fe}^{2+}, \mathrm{SO}_{4}{ }^{2-}, \mathrm{HS}^{-}, \mathrm{Mn}^{2+}, \mathrm{Cr}^{6+}, \mathrm{Zn}^{2+}, \mathrm{Cu}^{2+}$, and $\mathrm{Pb}^{2+}$ were used for the simulation input. Values for DOC, $\mathrm{Fe}^{2+}$, and $\mathrm{HS}^{-}$ were varied using experimentally measured ranges and concentrations of metals complexed with dissolved organics and precipitated as a sulfide phase were calculated. For the constructed high marsh, the sulfide pool is limited and abundant amounts of dissolved organic matter and dissolved iron are present. While experimental measurements confirm that trace metals remain in solution, modeling suggests that they are organic-metal complexes rather than free metals. Trace metals are thermodynamically favored to stay in dissolved form associated with dissolved organic matter. The abundance of dissolved carbon species provides binding sites for trace metals irrelevant of sulfide concentrations. Minteq simulations indicate that even if sulfide is high $(2 \mathrm{mM})$, metals such as $\mathrm{Cr}, \mathrm{Pb}, \mathrm{Zn}$, and $\mathrm{Mn}$ remain in solution as complexes with DOM (see Supplementary Table 4c).

A small experiment was conducted to voltammetrically determine the binding capacity of dissolved chromium with DOC as a function of depth (data not shown). The results indicated that near surface DOC had greater metal binding capacity than the DOC collected from pore-waters at greater depths. This implies that the trace metals complexed with organics near the surface may be more readily transported downward. Here, deeper into the sediments, higher levels of dissolved sulfide and organics with lower complexation capacities exist, promoting a prime environment for metal sulfide precipitation. These conditions would increase trace metal stability against re-oxidation and remobilization.

\subsection{Immobilization potential of the constructed and the natural marsh}

The maximum concentration of solid phase trace metal occurred at depths less than $30 \mathrm{~cm}$ in the constructed marsh (Fig. 3). The chemical profiles of pore-water from these depths indicate active sulfate reduction. Characteristic decreases in sulfate were accompanied by increases in dissolved sulfide concentrations (Fig. 2c and $\mathrm{d}$ ). Dissolved sulfide can readily form insoluble precipitates with dissolved trace metals. With the steady influx of sulfate from brackish tidal waters and abundance of DOC, continuous sulfate reduction can be sustained, which could result in the long-term accumulation of metal sulfides in these sediments.

Measurements for solid phase trace metals in the sediments from our study were supplemented with values from the MERI (2011) report, indicate no significant trends in metals except for lead in the constructed high marsh. Furthermore, the natural high marsh with the highest sulfate/sulfide concentrations, exhibited the lowest solid phase trace metal concentration in the sediments. These observations point to a mechanism that competes with sulfide-metal precipitation and accumulation.

Unexpectedly, the constructed marsh with its significantly lower concentrations of dissolved sulfide and similar dissolved metal concentrations ( $\mathrm{Cr}$ and $\mathrm{Cu}$ ) exhibited higher values of solidphase trace metals compared to the natural marsh sediment. One possible explanation may be that the constructed marsh, with a greater pool of FeS is more buffered against redox changes. Daily tidal fluctuations result in enhanced dissolved constituent transport, including oxygen, which might result in the re-oxidation of sulfides and release of any associated trace metal. This insoluble FeS may act as a buffer against the re-oxidation of sulfide associated solid-phase trace metals during low tides when less reducing conditions may be present. The presence of FeS phases in groundwater, for example, has been shown to consume dissolved oxygen and protect other redox active species such as $\mathrm{U}(\mathrm{VI})$ from reoxidation (Moon et al., 2009). Therefore, while in the natural marsh solid metal sulfides are not as well buffered against reoxidation as they are in the constructed marsh, where they are co-precipitated with substantially larger amounts of FeS, in the natural marsh they can remobilized flushed from the system.

In addition to buffering trace metals from reoxidation, FeS can play another role in increased trace metal immobilization. Trace metals are known to co-precipitate with insoluble FeS (Morse and Luther, 1999) and exchange with Fe in FeS (Hansen et al., 1996). So while iron may compete with trace metals for sulfide precipitation, it may lend another pathway to immobilization.

\section{Conclusions}

Organic metal complexation played an important role in the fate of trace metal distribution in the sediments. Organic ligands complexed with metals allowing for soluble metals even in the presence of sulfide.

- Although at specific depths, it appears the constructed high marsh immobilized larger concentrations compared to the constructed low marsh, depth averaged concentrations show no statistical differences.

- Comparing the three locations monitored, similar levels of immobilized trace metals were measured in the newly applied as well as the original sediments. Hence, there does not appear to be a continuous accumulation of trace metals in these sediments with time, but rather a dynamic metal cycling, which is affected by processes such as complexation of trace metals with DOC and tidally influenced oxidation of metal sulfides. 
- From the point of view of marsh restoration, this newly constructed marsh had a greater metal immobilization capacity compared to the natural marsh possibly due to buffering capacity of larger FeS pool. Once sediments have been under reducing conditions for extended time periods (decades or more), all bioavailable $\mathrm{Fe}(\mathrm{III})$ would have been reduced and $\mathrm{Fe}(\mathrm{II})$ transported out of the sediments, resulting in the sediment of the constructed marsh converging to that of the natural marsh including their metal retention capacity.

\section{Acknowledgments}

This research was supported by the Meadowlands Environmental Research Institute of the New Jersey Meadowlands Commission and the Gates Millennium Scholars Fellowship.

\section{Appendix A. Supplementary data}

Supplementary data associated with this article can be found, in the online version, at http://dx.doi.org/10.1016/j.ecoleng.2013. 06.018 .

\section{References}

ASTM, 2000. Standard Test Methods for Moisture, Ash, and Organic Matter of Peat and Other Organic Soils. Method D 2974-00. American Society for Testing and Materials, West Conshohocken, PA.

Blume, L.J., Schumacher, B.A., Shaffer, P.W., 1990. Handbook of Methods for Acid Deposition Studies Laboratory Analyses for Soil Chemistry. EPA/600/4-90/023. U.S. Environmental Protection Agency, Las Vegas, NV.

Catallo, W.J., 2003. Effects of static vs. tidal hydrology on pollutant transformation in wetland sediments. J. Environ. Qual. 32, 2421-2427.

Choi, J.H., Park, S.S., Jaffé, P.R., 2006. The effect of emerging macrophytes on the dynamics of sulfur species and trace metals in wetland sediments. Environ. Pollut. 140 (2), 286-293.

Du Laing, G., 2008. Factors affecting metal accumulation, mobility and availability in intertidal wetlands of the Scheldt estuary (Belgium). Wastewater treatment plant dynamics, and management in constructed and natural wetlands. Science, 121

Guy, R.D., Chakrabarti, C.L., 1976. Studies of metal-organic interactions in model systems pertaining to natural waters. Can. J. Chem. 54, 2600-2611.

Hansen, D.J., Berry, W.J., Mahony, J.D., Boothman, W.S., Di Toro, D.M., Robson, D.L., Ankley, G.T., Ma, D., Yan, Q., Pesch, C.E., 1996. Predicting the toxicity of metal-contaminated field sediments using interstitial concentration of metals and acid-volatile sulfide normalizations. Environ. Toxicol. Chem. 15 (12), 2080-2094.

Inglett, P.L., Reddy, K.R., Corstanje, R., 2005. Anaerobic soils. In: Hillel, D. (Ed.), Encyclopedia of Soils in the Environment. Elsevier, FL.
Kovaleva, S., 2004. Voltammetric determination of sulfide ions. J. Anal. Chem. 59 (8), 749-752.

Lasorsa, B., Casas, A., 1996. A Comparison of sample handling and analytical methods for determination of acid volatile sulfides in sediment. Mar. Chem. 52, 211-220.

Liao, N., 2007. QuikChem Method 10-116-29-3-A. Determination of Dissolved Sulfide by Flow Injection Analysis. Lachat Instruments, Loveland.

Ma, S., Luther, G.W., Keller, J., Madison, A.S., Metzger, E., Emerson, D., Patrick Megonigal, J., 2008. Tidal and seasonal variations of the sulfate ion in a New Jersey marsh system. Electroanalysis 20 (3), 233-239.

MacDonald, L.H., Paull, J., Jaffe, P., 2013. Enhanced semipermanent dialysis samplers for long-term environmental monitoring in saturated sediments. Environ. Monit. Assess. 185, 3613-3624.

MERI. Secaucus High School Marsh Sediment Study: April 2011. (2011).

Meysman, F.J.R.M.J.J., 2005. Acid-volatile sulfide (AVS) - a comment. Mar. Chem. 97 (3/4), 206L 212.

Moon, H.S., Komlos, J., Jaffé, P.R., 2009. Biogenic U(IV) oxidation by dissolved oxygen and nitrate in sediment after prolonged $\mathrm{U}(\mathrm{VI}) / \mathrm{Fe}(\mathrm{III}) / \mathrm{SO}_{4}{ }^{2-}$ reduction. J. Contam. Hydrol. 105, 18-27.

Morse, J.W., Luther III, G.W., 1999. Chemical influences on trace metal-sulfide interactions in anoxic sediments. Geochim. Cosmochim. Acta 63 (19/20), 3373-3378.

Nelson, D.W., Sommers, L.E., 1996. Total carbon, organic carbon, and organic matter. In: Page, A.L. (Ed.), Methods of Soil Analysis, Part 2. , 2nd ed. Agronomy, 9:9611010. Am. Soc. of Agron., Inc., Madison, WI.

Rao, C.R.M., Sahuquillo, A., Lopez Sanchez, J.F., 2008. A review of the different methods applied in environmental geochemistry for single and sequential extraction of trace elements in soils and related materials. Water Air Soil Pollut. 189, 291-333.

Saar, R.A., Weber, J.H., 1980. Lead(II)-fulvic acid complexes. Conditional stability constants, solubility, and implications for lead(II) mobility. Environ. Sci. Technol. $14(7), 877-880$.

Seybold, C.A., 2002. Soil redox, pH, temperature, and water-table patterns of a freshwater tidal wetland. Wetlands $22(1), 149-158$

Steinmann, P., 1996. Sampling anoxic pore-waters in peatlands using peepers for in situ-filtration. J. Anal. Chem. 354, 709-713.

Stookey, L.L., 1970. Ferrozine - a new spectrophotometric reagent for iron. Anal. Chem. 779 .

Sundelin, B., Erikkson, A., 2001. Mobility and bioavailability of trace metals in sulfidic coastal sediments. Environ. Toxicol. Chem. 20 (4), 748-756.

Suntornvongsagul, K., Burke, D., Hahn, D., 2007. Uptake and translocation of heavy metals in salt marsh sediments by Spartina patens. Bull. Environ. Contam. Toxicol. $78(3 / 4), 275-279$.

Taillefert, M., 2002. The influence of sulfides on soluble organic-Fe(III) in anoxic sediment pore-waters. Estuaries 25 (6a), 1088L 1096.

Van den Berg, C.M.G., Merks, A., Duursma, E.K., 1987. Organic complexation and its control of the dissolved concentrations of copper and zinc in the Scheldt estuary. Estuar. Coast. Shelf Sci. 24 (6), 785-797.

Vymazal, J., Jaroslav, S., Nemcova, J., Suchy, V., 2010. Heavy metals in sediments from constructed wetlands treating municipal wastewater. Biogeochemistry 101 (1), 335-356.

Webster, I., 1998. Theoretical and experimental analysis of peeper equilibration dynamics. Environ. Toxicol. Chem. 32, 1727-1733.

Wenning, R.J., Bonnevie, N.L., Huntley, S.L., 1994. Accumulation of metals, polychlorinated biphenyls, and polycyclic aromatic hydrocarbons in sediments from the lower Passaic River, New Jersey. Arch. Environ. Contam. Toxicol. 27, 64-81. 